\title{
COVID-19 vaccination certificates and lifting public health and social measures: ethical considerations
}

\author{
Teck Chuan $\mathrm{Voo}^{1}$, Maxwell J. Smith², Ignacio Mastroleo ${ }^{3}$, Angus Dawson4, WHO Ethics \& COVID-19 Working Group*
}

${ }^{1}$ Centre for Biomedical Ethics, Yong Loo Lin School of Medicine, National University of Singapore, Singapore (Correspondence to: T.C. Voo: medvtc@ nus.edu.sg). ${ }^{2}$ Faculty of Health Sciences, University of Western Ontario, London, Ontario, Canada. ${ }^{3}$ National Scientific and Technical Research Council, Buenos Aires, Argentina. ${ }^{4}$ Sydney Health Ethics, Sydney School of Public Health, University of Sydney, Sydney, New South Wales, Australia

*WHO Ethics \& COVID-19 Working Group

\begin{abstract}
Background: To reopen society, various countries are planning or have implemented differential public health and social measures (PHSMs) for COVID-19-vaccinated individuals, by exempting these individuals from some of the measures.

Aims: To examine the ethical considerations raised by differential PHSMs by differrnt countries based on individual vaccination status verified by vaccination certificates.

Discussion: Decisions on whether and when measures should be lifted specifically for vaccinated individuals should be guided by scientific and ethical considerations. These considerations include the public health risks of differential lifting, particularly in a context where a substantial portion of society is not vaccinated; mitigation of inequities and unfair disadvantages for unvaccinated individuals; and whether to permit other health certificates or credentials besides proof of vaccination as alternative options to access specific activities or services, as a way to balance public health and freedom of movement.

Conclusion: Vaccination certificates may undermine a population-based approach to COVID-19 vaccination to achieve and accelerate universal lifting of PHSMs, result in unfair and inequitable health and social outcomes, and generate social divisions at a time when solidarity within (and between) countries is necessary to navigate the pandemic and its burdens. Further research on the ethical acceptability and impact of COVID-19 vaccine certificates in countries that have implemented them should be carried out to inform future ethical considerations on this issue.

Keywords: COVID-19, ethics, pandemic, vaccination, vaccination certificates

Citation:Voo TC; Smith MJ; MastroleoI; Dawson A. COVID-19 vaccination certificates and lifting public health and social measures: ethical considerations. East Mediterr Health J. 2022;28(6):454-458. https://doi.org/10.26719/emhj.22.023

Received:15/07/21; accepted: 29/07/21

Copyright (C) World Health Organization (WHO) 2022. Open Access. Some rights reserved. This work is available under the CC BY-NC-SA 3.0 IGO license (https://creativecommons.org/licenses/by-nc-sa/3.o/igo)
\end{abstract}

\section{Introduction}

During the response to the COVID-19 pandemic, a range of public health and social measures (PHSMs) were introduced to reduce transmission and protect society from harm (1). COVID-19 vaccination is a key public health intervention to prevent severe illness and death and reduce disease spread, and hence eligible populations should have equal access to the vaccines and be vaccinated. As an increasing proportion of their populations is being vaccinated, or when a high population vaccination rate has been achieved, policy-makers must decide whether or when PHSMs should be lifted or relaxed, and for whom. One question is whether, and under what conditions, it would be ethically acceptable to lift certain PHSMs - such as mask wearing, social and physical distancing (e.g. restrictions on domestic movement and size of gatherings), confinement orders (e.g. quarantine and isolation) and international travel-related measures - for individuals who have been vaccinated while maintaining those measures for those who have not. This approach is referred to as differential PHSMs. This may be done through public health advice regarding the measures that do not apply to vaccinated individuals, or by making proof of vaccination a condition for access to some places or activities. Some countries have deployed the latter approach by issuing vaccination certificates for access to community activities, and/or have set up the infrastructure for international travel applications (2), whereas other countries have not done so or have enacted limitations on their uses. As a measure to reopen society and reduce socioeconomic burdens for individuals, groups and businesses during the COVID-19 pandemic, vaccination certificates require heightened ethical scrutiny because of current unequal or inequitable access to COVID-19 vaccines and thus to the benefits of vaccination certificates, and other ethical issues (2-6).

\begin{abstract}
Aims
The World Health Organization (WHO) Ethics \& COVID-19 Working Group consists of bioethicists and public health practitioners from a wide range of countries representing all WHO Regions. As members of this working group, we examine the ethical issues and considerations raised by differential PHSMs based on individual COVID-19 vaccination status verified by
\end{abstract}


vaccination certificates, with a focus on their domestic deployment. The paper does not discuss the use of vaccination certificates for international travel, which, at time of writing, is not supported by the WHO. (7). It also does not discuss ethical issues associated with the related but distinct issue of immunity certificates for recovered individuals nor those associated with the related but distinct issue of employers making COVID-19 vaccination a requirement for employment, both of which have been discussed elsewhere $(8,9)$.

\section{Discussion}

\section{WhatAreAvaccinationAertificates $\breve{A}$}

A vaccination record documents the administration of a vaccine to an individual and related data such as dose number and date of vaccination. It does not serve as proof of immunization status, which is medical information or history that is used (by healthcare professionals) for medical care purposes. A vaccination certificate or pass, on the other hand, documents individual vaccination status that may be verified by a third party to exempt the holder from a range of PHSMs (e.g. quarantine after exposure), or to permit access to a range of venues, services or activities; particularly those that involve high risk (e.g. domestic interstate travel, and mass gathering events). The public health rationale of vaccination certificates is to implement a risk-stratification approach based on the view that access or exemptions ought to be authorized only for vaccinated individuals due to their (substantially) lower risk for infection and transmission.

\section{LiftingAublichealthandAocialAmeasuresAnderA scientificAuncertainty}

Decisions by policy-makers to lift PHSMs, including the use of vaccination certificates to implement differential PHSMs, should be grounded in a risk-based approach. Relevant features of risk assessment and management of individual vaccination status as a condition for access to some activities include evidence (and any relevant uncertainty) about the effectiveness and duration of action of COVID-19 vaccines in reducing the risks of mortality, severe disease, infection, and virus transmission. Changes in these factors over time and the impact of variants as they emerge should be reviewed continuously.

As current authorized COVID-19 vaccines have demonstrated effectiveness in preventing severe disease and death, it might appear that PHSMs, such as physical distancing and travel restrictions, are no longer necessary for vaccinated individuals. However, although there is evidence that vaccination also leads to protection against infection and a reduction in transmission, the extent to which each vaccine prevents transmission of SARS-CoV-2 to susceptible contacts remains uncertain. It is not known how long each vaccine confers protection on individuals, and the extent to which vaccine efficacy and effectiveness may be affected by new variants remains uncertain. There is also no clear understanding of the population level of vaccination coverage required for herd immunity, and if such an outcome is possible. For these reasons, where a substantial proportion of a society is not vaccinated, the ethical obligation to protect public health suggests that caution should be exercised in lifting PHSMs, even for vaccinated individuals, as this may contribute to SARS-CoV-2 spread and potentially to severe cases and deaths.

\section{EquityAndffairness}

COVID-19 vaccination is currently slow and uneven in many countries due to inequities in vaccine allocation, and issues such as inefficient vaccine delivery. Given the scarcity of vaccines, countries that have secured doses should designate priority groups for vaccination that are at high or elevated risk of infection and transmission, or of severe disease or death, considering epidemiological and vaccine supply conditions (10). Prioritization of vaccination is justified because it addresses populationlevel outcomes and relies on solidarity, whereby some wait for an opportunity to be vaccinated for the good of others considered to be at greater risk. It may be seen as a further disadvantage or an injustice if individuals in nonprioritized groups not only bear a greater risk for the good of society but also cannot equally benefit from the lifting of PHSMs. In domestic settings with limited vaccine supply, the systematic issue of vaccination certificates, particularly if they become a requirement for accessing a wide range of activities (as opposed to 1 option among other health credentials - discussed below), is likely to exacerbate existing inequities or create new inequities in health and in participation in civil, social and economic life.

Where vaccine supply is adequate, a substantial fraction of people would likely remain unvaccinated through no fault of their own, such as those who cannot be vaccinated because of medical contraindications; those who are ineligible for vaccination under country-specific regulation (e.g. children); and hard-to-reach populations (e.g. because of geography, nomadic movement and insecure residency status) (11).

There would also be individuals who are hesitant about being vaccinated for reasons that include lack of trust in science, in the specific vaccine offered (which might be due to misinformation), or in health or other governmental authorities (12, 13). While differential PHSMs could incentivize vaccine uptake, they might also be regarded as a coercive approach, especially by those who lack trust, and could increase vaccine hesitancy. Policy-makers should seek the reasons for vaccine hesitancy and the extent to which vaccination certificates would increase it, and address the concerns of vaccinehesitant individuals to increase vaccine uptake before they implement differential PHSMs as a direct or indirect way to compel vaccination. Otherwise, there is a danger that differential PHSMs for unvaccinated individuals could increase mistrust and potentially create inequity.

To mitigate inequities and unfair disadvantages, differential PHSMs should be introduced only where 
there is equal or wide access to a vaccine and to the opportunity of obtaining a vaccination certificate. Differential PHSMs through vaccination certificates should also only be a temporary measure. Universal lifting of COVID-19 PHSMs - by suppressing transmission and vaccinating a large number of populations - should remain the ultimate societal goal, as it will promote equal restoration of liberties and opportunities to participate in civil, social and economic life.

\section{ExemptionsffromAertification}

Where access to a range of activities or settings is restricted to those who have a vaccination certificate (as opposed to a health credential option among others), policy-makers should consider a parallel system for recording and verifying exemptions from the need to obtain and use a vaccination certificate for such access, based on inability to be vaccinated because of medical or other reasons provided for in law or relevant regulations. Key considerations are the risk to vaccine uptake and to achieving a sufficient, sustained vaccination coverage rate. For this reason, it is easier to support individual exemptions from holding a vaccination certificate as an access requirement for those who are not vaccinated because of medical ineligibility. Allowing exemptions based on personal beliefs against vaccination in general or specifically to COVID-19 vaccines could undermine the achievement of high vaccination coverage, which would benefit all by facilitating the lifting of PHSMs for everyone in a given society. Where personal belief exemption from the access requirement of having a vaccination certificate is not allowed to protect public health and societal goals, the disadvantages of not having a vaccination certificate, including potential long-term restrictions, should be communicated to the public.

\section{BalancingApublicAealthAndAibertyA}

In a context where PHSMs are broad and highly restrictive, it may be argued that policy-makers should focus on maximizing liberty by introducing vaccine certificates to reduce the number of individuals affected by the restrictions of PHSMs. A focus on liberty maximization perse is ethically problematic if it means that many people in society will be significantly disadvantaged by lack of access to the benefits of removal of PHSMs through no fault of their own (e.g. if they are not in a priority group for vaccination). The aim of vaccination is to protect individuals and society as a whole. The choice by policymakers not to implement differential PHSMs through vaccination certificates would affirm that the response to COVID-19 is a societal one and should not create new forms of disadvantage.

Even if differential PHSMs are considered justified to maximize liberty, vaccination certificates should not be required to access goods and services that support the basic necessities of daily life (e.g. health and social services, grocery shopping, and public transport). Any potentially increased risk that those with no certificate might pose to others in such essential activities could be mitigated by continuing use of PHSMs by everyone (e.g. wearing a mask, and physical distancing) as well as broader public health measures such as contact tracing and quarantine after exposure.

Introduction of differential PHSMs for vaccinated and unvaccinated individuals need not make vaccination certificates a categorical requirement for entry into a place or service. Another way to balance public health and liberty by introducing differential PHSMs would be to relax restrictions for vaccinated individuals without excluding unvaccinated individuals. For example, some countries have adopted a policy of allowing individuals to access particular places or mass gathering events if they have either a COVID-19 vaccination certificate or a negative test as a health credential that their risk of infecting others is within acceptable limits (14). Where differential PHSMs are implemented, facilitating the use of other health credentials or certificates besides proof of vaccination, such as reliable COVID-19 negative test results and making testing accessible to all, or issuing immunity certificates (based on reliable tests for infection-acquired immunity) for recovered individuals, would protect freedom of movement and other liberties (15), and ensure that measures for nonvaccinated individuals are proportionate and socially inclusive (defined here as removing or reducing barriers that prevent people from participating in civil, social and economic life). The feasibility of differential certification, the risks of infection and transmission resulting from such a measure (in conjunction with appropriate PHSMs), and the extent to which it mitigates inequities and disadvantages (especially for already disadvantaged or marginalized groups) and protects freedom of movement in a given context should be studied.

\section{SocialAdivisionAndAsegregation}

Use of vaccination certificates as part of a move to reduce PHSMs is likely to increase social inequalities and divisions between vaccinated and unvaccinated individuals. Even if vaccination certificates are not imposed as a governmental or business requirement to access a mass gathering or other congregate settings, vaccinated and unvaccinated individuals might be required to segregate by assignment to different areas, e.g. to different airplane cabins or different sections of a stadium, which may be socially divisive and result in the stigmatization of unvaccinated individuals. Such social divisions should be avoided when PHSMs could be required to minimize the risks of congregation, or when there is scientific evidence that segregation according to individual vaccination status does not significantly reduce public health risks.

\section{Conclusions}

Differential PHSMs with vaccination certificates raise significant ethical concerns. They could undermine a population-based approach to COVID-19 vaccination to achieve and accelerate universal lifting of PHSMs, result 
in unfair and inequitable health and social outcomes, and generate social divisions at a time when a solidarity-based approach within (and between) countries is necessary to navigate the pandemic and its burdens. Further research on the ethical acceptability and impact of COVID-19 vaccine certificates in countries that have implemented them should be carried out to inform future ethical considerations on this issue.

\section{Acknowledgement}

This article was produced by the WHO Ethics and COVID-19 Working Group. Drafting was led by Teck Chuan Voo, Maxwell J. Smith, Ignacio Mastroleo, and Angus Dawson, with guidance from the Working Group's co-chairs Beatriz Thomé and Ross Upshur, and contributions from: Thalia Arawi, Oumou Younoussa Bah Sow, Jean-François Delfraissy, Ezekiel Emanuel, Tina Garanis-Papadatos, Prakash Ghimire,, Zubairu Iliyasu, Sharon Kaur, Ruipeng Lei, Roli Mathur, Signe Mezinska, Keymanthri Moodley, Kaori Muto, Michael Parker, and Carla Saenz. We would like to thank Andreas Reis, Katherine Littler, Patrik Hummel, Liz Mumford and Lee-Anne Pascoe from the WHO Health Ethics and Governance Unit for providing secretariat support for the drafting of this paper. Contributions and feedback from staff of the WHO Departments of Immunization, Vaccines and Biologicals (Joachim Maria Hombach and Katherine O'Brien) and Acute Events Management (Abdirahman Mahamud), and members of the WHO ACT-A Ethics and Governance Working Group (Calvin WL Ho, Ehsan Shamsi Gooshki, Jonathan Wolff, Owen Schaefer, Ruth Faden and Sonali Kochhar) are duly acknowledged.

Funding: None

Competing interests: None declared.

\section{Certificats de vaccination contre la COVID-19 et levée des mesures de santé publique et sociales : considérations éthiques}

\section{Résumé}

Contexte : Afin de procéder à la réouverture des sociétés, plusieurs pays prévoient ou ont mis en œuvre des mesures de santé publique et sociales différentielles pour les personnes vaccinées contre la COVID-19, en exemptant ces personnes de certaines de ces mesures.

Objectifs : Examiner les considérations éthiques soulevées par les mesures de santé publique et sociales par divers pays selon le statut vaccinal individuel vérifié au moyen des certificats de vaccination.

Discussions: Les décisions relatives à la possibilité et au temps opportun pour la levée des mesures visant spécifiquement les personnes vaccinées doivent être guidées par des considérations scientifiques et éthiques. Au nombre de ces considérations figurent les risques qu'une levée différentielle représente pour la santé publique, notamment lorsqu'une large part de la société n'est pas vaccinée ; l'atténuation des inégalités et des désavantages injustes pour les personnes non vaccinées ; et la question de savoir s'il convient d'autoriser d'autres certificats ou justificatifs sanitaires que la preuve de vaccination comme options alternatives pour accéder à des activités ou services spécifiques, en tant que compromis entre la santé publique et la liberté de circulation.

Conclusion: Les certificats de vaccination peuvent affaiblir une approche de la vaccination contre la COVID-19 fondée sur la population afin d'obtenir et d'accélérer la levée universelle des mesures de santé publique et sociales, entraîner des résultats sanitaires et sociaux injustes et inéquitables et générer des divisions sociales à un moment où la solidarité au sein des pays (et entre eux) est nécessaire pour faire face à la pandémie et aux fardeaux qu'elle représente. D'autres recherches sur l'acceptabilité éthique et l'impact des certificats de vaccination contre la COVID-19 dans les pays qui les ont mis en œuvre devraient être menées afin d'éclairer les futures considérations éthiques sur cette question.

$$
\begin{aligned}
& \text { شهادات التطعيم ضد كوفيد-19 ورفع التدابير الصحة العامة والتدابير الاجتماعية: اعتبارات أخلاقية }
\end{aligned}
$$

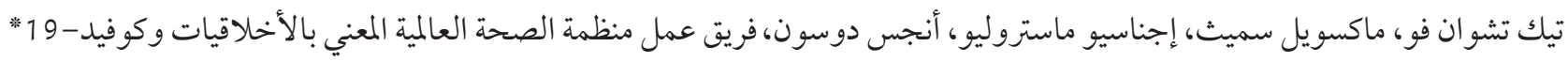

$$
\begin{aligned}
& \text { الخلاصة } \\
& \text { الخلفية: حتى يتسنى إعادة فتح المجتمعات، تعتزم بلدان عديدة تنفيذ تدابير صحة عامة وتدابير اجتماعية تفاضلية للأفر اد المُلقّحين ضد كو فيد فيد- }
\end{aligned}
$$

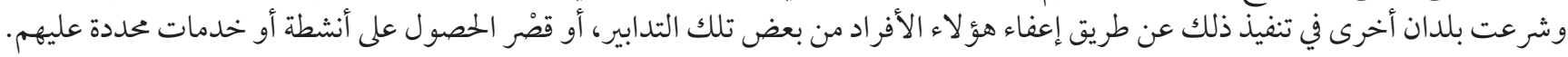

$$
\begin{aligned}
& \text { الأهداف: هدفت هذه الدراسة إلى دراسة الاعتبار ات الأخلاقية التي ينطوي عليها تطبيق تدابير الصحة العامة والتدابير الاجتهاعية التفاضلية في }
\end{aligned}
$$

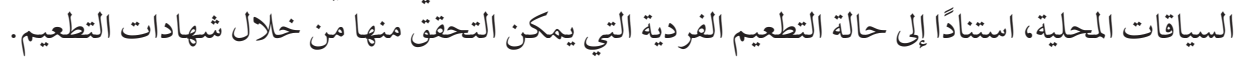




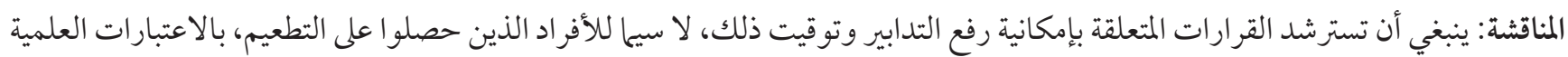

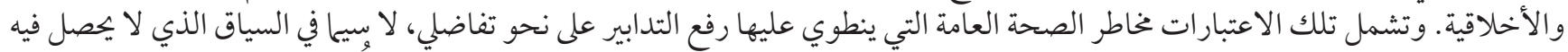

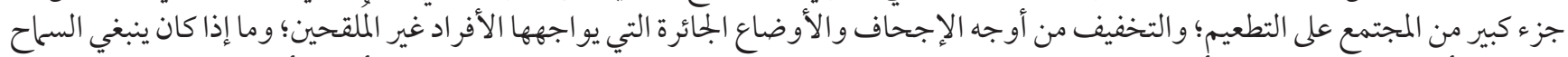

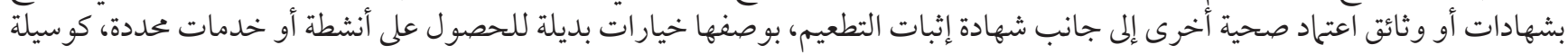
لتحقيق التوازن بين الصحة العامة وحرية التنقل.

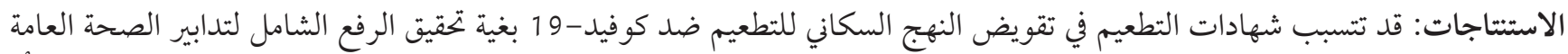

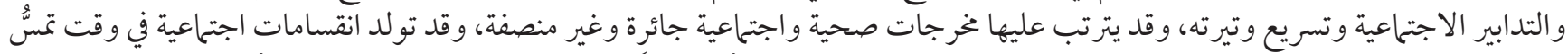

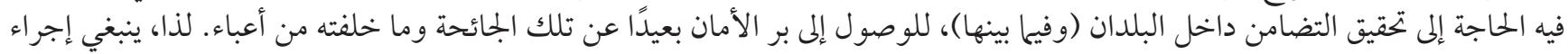

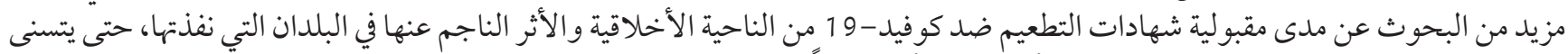
الاسترشاد بها في تحديد الاعتبارات الأخلاقية بشأن هذه المسألة مستقبلا.

\section{References}

1. Interim guidance: considerations for implementing and adjusting public health and social measures in the context of COVID-19. Geneva: World Health Organization; 2021 (https://www.who.int/publications/i/item/considerations-in-adjusting-public-healthand-social-measures-in-the-context-of-covid-19-interim-guidance, accessed 7 July 2021).

2. Twelve criteria for the development and use of COVID-19 vaccine passports. London: The Royal Society; 2021 (https://royalsociety.org/-/media/policy/projects/set-c/set-c-vaccine-passports.pdf, accessed 7 July 2021).

3. What place should COVID-19 vaccine passports have in society? London: Ada Lovelace Institute; 2021 (https://www.adalovelaceinstitute.org/summary/covid-19-vaccine-passports/, accessed 7 July 2021).

4. Hall MA, Studdert DM. "Vaccine passport” certification - policy and ethical considerations. N Engl J Med. 2021 Sep 9;385(11):e32. https://doi.org/10.1056/NEJMp2104289 PMID:33789006

5. Requiring proof of Covid-19 vaccination (vaccine "passports"/ "certificates"): key ethical, legal, and social issues. Bern: National COVID-19 Science Task Force; 2021 (https://sciencetaskforce.ch/wp-content/uploads/2021/02/Vaccination_certification_requirements_ELSI19Feb21-EN.pdf, accessed 7 July 2021)

6. Special rules for vaccinated people? Ad hoc recommendation [English translation]. Berlin: Ethics Council; 2021 (https://www. ethikrat.org/fileadmin/Publikationen/Ad-hoc-Empfehlungen/englisch/recommendation-special-rules-for-vaccinated-people.pdf, accessed 7 July 2021).

7. Interim position paper: Considerations regarding proof of COVID-19 vaccination for international travellers. Geneva: World Health Organization; 2021 (https://www.who.int/news-room/articles-detail/interim-position-paper-considerations-regarding-proof-of-covid-19-vaccination-for-international-travellers, accessed 7 July 2021).

8. Voo TC, Reis AA, Thomé B, Ho CWL, Tam CC, Kelly-Cirino C et al. Immunity certification for COVID-19: ethical considerations. Bull World Health Organ. 2021 Feb 1;99(2):155-61. https://doi.org/10.2471/BLT.20.280701 PMID:33551509

9. World Health Organization. COVID-19 and mandatory vaccination: Ethical considerations: policy brief. Geneva: World Health Organization 2022 (https://apps.who.int/iris/handle/10665/354585, accessed 1 June 2022).

10. WHO SAGE roadmap for prioritizing uses of COVID-19 vaccines in the context of limited supply. Geneva: World Health Organization; 2020 (https://www.who.int/publications/i/item/who-sage-roadmap-for-prioritizing-uses-of-covid-19-vaccines-in-the-context-of-limited-supply, accessed 7 July 2021)

11. Ozawa S, Yemeke TT, Evans DR, Pallas SE, Wallace AS, Lee BY. Defining hard-to-reach populations for vaccination. Vaccine. 2019 Sep 3;37(37):5525-34. https://doi.org/10.1016/j.vaccine.2019.06.081 PMID:31400910

12. Lazarus JV, Ratzan SC, Palayew A, Gostin LO, Larson HJ, Rabin K et al. A global survey of potential acceptance of a COVID-19 vaccine. Nature Med. 2021 Feb;27(2):225-8. https://doi.org/10.1038/s41591-020-1124-9 PMID:33082575

13. MacDonald NE, SAGE Working Group on Vaccine Hesitancy. Vaccine hesitancy: definition, scope and determinants. Vaccine. 2015 Aug 14;33(34):4161-4. https://doi.org/10.1016/j.vaccine.2015.04.036 PMID:25896383

14. Murray A. Coronapas: The passport helping Denmark open up after Covid. BBC News, 21 April 2021 (https://www.bbc.com/news/ world-europe-56812293, accessed 7 July 2021)

15. The Council of Europe Committee on Bioethics (DH-BIO). Statement on Human Rights Considerations Relevant to "Vaccine Pass" and Similar Documents; 2021 (https://rm.coe.int/dh-bio-2021-7-final-statement-vaccines-e/1680a259dd, accessed 7 July 2021) 